\title{
Progressive combustion in SI-Engines-Experimental investigation on influence of combustion related parameters
}

\author{
R HARISH KUMAR ${ }^{1}$ and A J ANTONY ${ }^{2}$ \\ ${ }^{1}$ Department of Mechanical Engineering, Sri Siddhartha Institute of Technology, \\ Maralur, Tumkur 572105 \\ ${ }^{2}$ Department of Mechanical Engineering, Sahyadri Institute of Technology, \\ Mangalore 575009 \\ e-mail: rhkmechssit@gmail.com; rhkmechssit@yahoo.co.in
}

MS received 10 September 2007; revised 6 May 2008

\begin{abstract}
The fuel heat release rate which virtually controls the combustion process is dependent on the 'Mass-Fraction-Burnt (MFB)'. In the present research work, a 'logistic model with conditional variability in MFB', has been developed for precise simulation of combustion in SI engines as the model has built in routines to take into account such factors as location of spark plug, single/dual spark plugs, intake generated swirl, combustion chamber geometry (associated with Bore/Stroke ratio), etc. A major contribution of this paper is that new and improved models for the 'overall combustion duration', and 'ignition delay/flame development angle', taking into account primarily the influence of compression ratio on the overall combustion process in SI engine have been developed. Taylor's original equation for estimating the overall combustion duration has been modified by including a logistic equation for the error term and incorporating it in the original equation. Ignition delay as proposed by Keck et al has been modified by incorporating a polynomial of $3^{\text {rd }}$ order into the original equation. The empirical correlations that have been proposed in this paper may serve to be the starting point for simulation of 'photodetonation concept' to simulate HCCI combustion which is presently the hot research work in the area of pre-mixed combustion.

A program in Turbo-C++ has been developed for the complete simulation of SI engine combustion, taking into account the conditional variability effect, variable specific heats of burnt gases, dissociation of gases at high temperatures, progressive combustion phenomena, heat transfer (based on Woschni 's equation), gas exchange process based on 1D-steady gas flow equation employing Taylor's mach index of $0 \cdot 6$ for valve design.
\end{abstract}

Keywords. MFB; logistic model; combustion duration; ignition delay.

\section{Introduction}

Researchers in the past have tackled the prediction of burning rates by assuming a laminar flame propagation model with a suitable multiplying factor for turbulence effects as 
propounded by Annand (1971). However, no guidance is available for the choice of such a factor for varying operating conditions. Blizard \& Keck (1974), in their paper, have reported a model based on the concept of eddy entrainment by the flame front. However, they feel that more detailed investigation is needed to verify the assumed correlations regarding the characteristic eddy radius and the turbulent entrainment velocity. Heywood et al (1979) have advocated use of the Weibe function and actual mass fraction burned curves have been fitted with Weibe form factor $=5$ and Weibe efficiency factor $=2$. Ball et al (1988) have investigated the use of a two zone model to determine the information about the burnt and unburnt gas temperature and crevice gas burn up, incorporating polytropic indices for compression and expansion, retaining the simplicity and computational efficiency of Rassweiler and Withrow. Their model is not however reliable, owing to temperature gradients in the burnt zone and disproportionately high rate of heat transfer from the mixture that burns first during combustion. The mass fraction burned calculations using this model were also found to be not so accurate as those based on simpler models. Heywood \& Pischinger (1990) developed a model for the flame kernel formation in SI-engines that computed the flame kernel radius as a function of time accounting for the electrical characteristics of the spark discharge, effect of heat losses to electrodes, spark plug geometry, convection velocity of the mean flow, etc. The major drawback of their model is that it can only compute the flame kernel growth over a relatively short time (less than $1 \mathrm{~ms}$ ), chiefly because the breakdown energy was not taken into account. Hinze \& Heywood $(1992 ; 1996)$ have developed a more complete model to describe the flame kernel growth taking the above factor into account including the effects of flame curvature, turbulent wrinkling during combustion, spark plug geometry, etc. Jensen \& Schramm (2000) present a three zone heat release model which includes the effect of crevice, based on the thermodynamic analysis of three connected zones comprising the burned gas, unburnt gas, and gas trapped in crevices.

\section{Development of the mathematical model (experimental procedure included)}

Despite the several limitations of the Rassweiler and Withrow model for computing the MFB, which includes among others, its inability to account for crevice volumes, its sensitivity to selection of appropriate polytropic index during compression and combustion process, its inability to predict accurately the end of combustion (EOC), and its poor accountability of heat transfer effects, studies by researchers clearly points to the fact that it is still a preferred model for its simplicity and for its computationally undemanding requirements, while being almost as accurate as more complex models. In the present work therefore, this equation has been used for estimation of mass fraction burnt during combustion.

$$
\begin{aligned}
M F B & =\sum_{0}^{i} P i / \sum_{0}^{n 1} P i \\
& =\left[\left(V * P^{1 / n 1}-V_{s} * P_{s}^{1 / n 1}\right) /\left(V_{f} * P_{f}^{1 / n 1}-V_{s} * P_{s}^{1 / n 1}\right)\right] .
\end{aligned}
$$

The governor sleeve displacement and the carburetor float level were set to give near stochiometric F/A ratios when operating at WOT conditions. Log (P) vs. Log (V) plots of the experimental $P-\theta$ trace were obtained for different compression ratios keeping engine operating speed, constant (figures 1 to 4 ).

The compression and expansion processes on such a log-log diagram are nearly straight lines. The point where the above graph deviates sharply from the straight line representing 

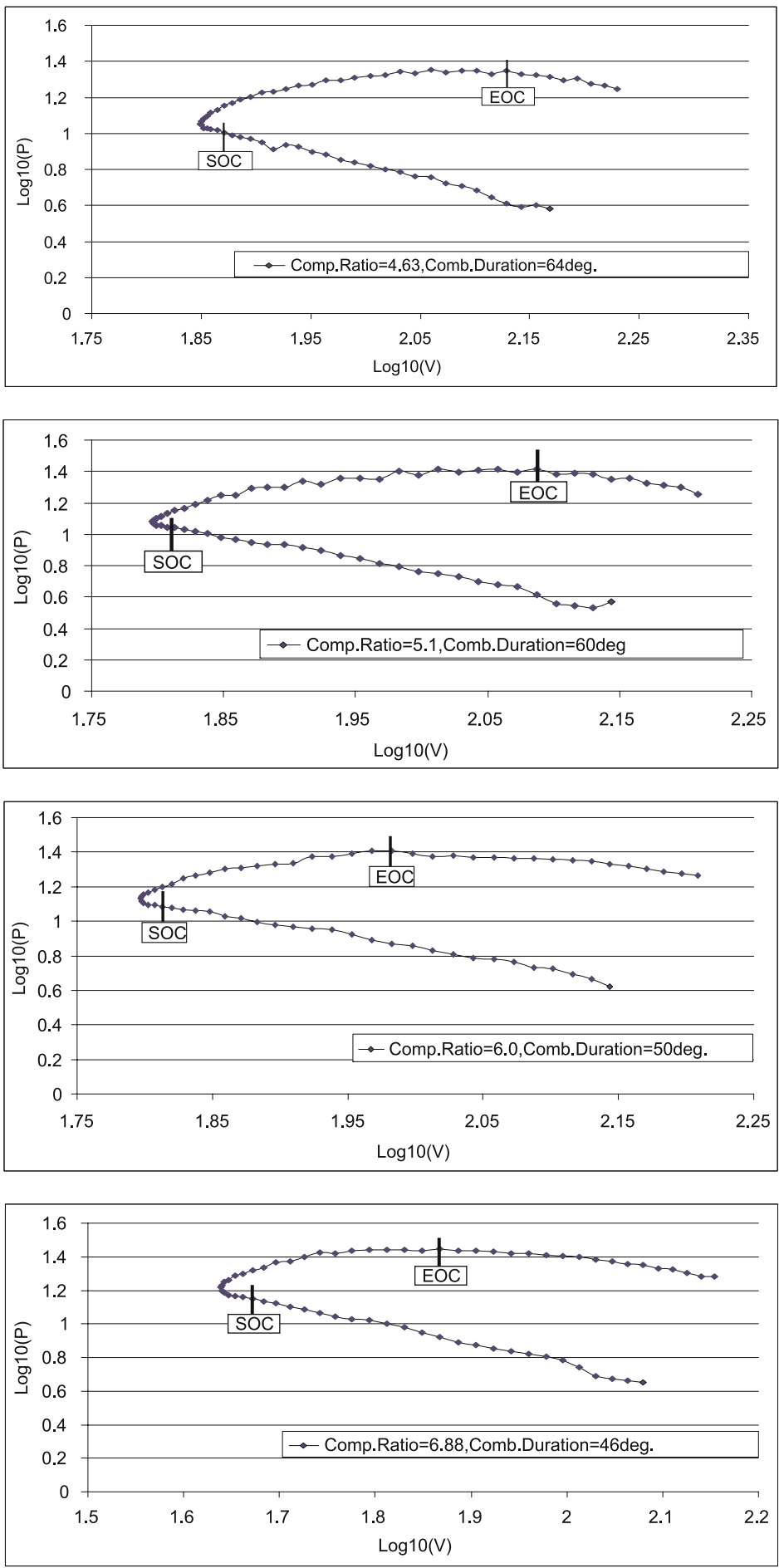

Figures 1-4. $\log (\mathrm{P})$ vs. $\log (\mathrm{V})$ Plots. 
the compression process was considered as start of combustion (SOC). Similarly, the point where the above log-log graph approaches sharply the straight line representing the expansion process was identified as the end of combustion (EOC). The 'overall combustion duration', (crank angle between SOC and EOC), could therefore be measured very accurately from the experimental $P-\theta$ trace and the same is given in the form of table. To improve the accuracy of determination of overall combustion duration using this conventional approach, the authors have replotted the graphs to several times their normal size. The 'scaled up' graphs have been graphically analysed point by point (to an accuracy of $\pm 0 \cdot 5^{\circ}$ crank angle) and the slope at each of these points have been measured. The section of the graph where there is sharp difference in the slope between adjacent points has been identified as 'SOC'. 'EOC' has been determined in a similar fashion. This approach provides not only a simple but an effective and accurate method to determine the overall combustion duration in the opinion of the authors (table 1).

Taylor's equation which is widely used for determining the overall combustion duration in its original form is given as

$$
\Delta \theta c=40+5 *((n / 600)-1)+\left(166 *\left(((12 \cdot 5 / Y)-1 \cdot 1)^{2}\right)\right) .
$$

Evidently this equation considers only the engine speed and equivalence ratio to determine the overall combustion duration expressed in terms of degrees of crank rotation. However from the graphs of figures ( 1 to 4 ), there is enough experimental evidence to suggest that the overall combustion duration indeed depends on the compression ratio of the engine, as much as the other two factors. Taylor's equation obviously predicts the same value for all the compression ratios (66 deg). The error between the original equation and the experimental values as given in the table 1 are tabulated below (table 2).

From the above table an error curve was fitted in the form of a logistic equation and the error in the original Taylor's equation was minimised by incorporating this equation into it, thereby giving the modified Taylor's equation.

$$
\begin{aligned}
\Delta \theta c= & \left(40+(5 *((n / 600)-1))+166 *\left(((12 \cdot 5 / Y)-1 \cdot 1)^{2}\right)\right. \\
& -(37 \cdot 71 /(1+(2411 * \exp (-1 \cdot 2 * r))))) .
\end{aligned}
$$

Empirical flame combustion models have difficulty to appropriately describe the 3 phases of combustion, viz. the flame development phase, the rapid burn phase, the flame termination phase, with sufficient generality to be widely useful. Usage of 2-Zone model (burnt and unburnt regions being separated by a thin reaction flame sheet) together with coupled analysis of flame front location and cylinder pressure data, gives the following burning law which is used as a first step towards the model building.

$$
d / d t(m b)=\rho_{u} * A_{f} * S_{l}+\mu / \tau .
$$

Table 1. Experimental values of overall combustion duration for varying compression ratio.

\begin{tabular}{lccccccc}
\hline$r$ & 4.63 & $5 \cdot 10$ & $6 \cdot 0$ & $6 \cdot 88$ & $7 \cdot 40$ & $8 \cdot 28$ & $9 \cdot 16$ \\
$\Delta \theta c$ & 64 & 60 & 50 & 46 & 36 & 32 & 30 \\
\hline
\end{tabular}


Table 2. Error between the experimental values of overall combustion duration and that based on original Taylor's equation.

\begin{tabular}{lccccccc}
\hline$r$ & 4.63 & $5 \cdot 10$ & $6 \cdot 0$ & $6 \cdot 88$ & $7 \cdot 40$ & $8 \cdot 28$ & $9 \cdot 16$ \\
Error & 02 & 06 & 16 & 20 & 30 & 34 & 36 \\
\hline
\end{tabular}

Equation 3, when effectively integrated over the relevant portion of the total combustion process, assuming the turbulent characteristic velocity as proportional to mean piston speed, an equation for the flame development angle could be obtained as

$$
\Delta \theta d=C *(V p * \gamma)^{1 / 3} *\left(h / S_{l}\right)^{2 / 3}(C \text { has to be evaluated }) .
$$

The above equation as proposed by Keck et al is applicable to SI engines in general but does not take into account the parameters related to engine geometry especially the location of the spark plug, swirl generation during intake process and the effect of compression ratio, etc. In the present paper, the influence of the above parameters have been indirectly taken into account by fitting it with a 'Polynomial Equation of the $3^{\text {rd }}$ order', by minimization of error using non-linear regression analysis.

The evaluation of the constant ' $\mathrm{C}$ ', in equation 4 , has been done using this model and therefore, the authors believe, it must yield a more accurate prediction of the flame development phase in SI engine combustion.

$$
\begin{aligned}
S_{l o} & =0.263+\left[-0.847 *(\Phi-1.13)^{2}\right] \\
\alpha & =2.18-[0.8 *(\Phi-1)] \\
\beta & =-0.16+[0.22 *(\Phi-1)] \\
S_{l} & =S_{l o} *(T i / 298)^{\alpha} *(p / 1030000)^{\beta} .
\end{aligned}
$$

Equations 5, 6, 7, 8 are used to evaluate the laminar flame speed $\left(S_{l}\right)$, which upon substitution in equation 2, enables $C$ to be evaluated if experimental values of $\Delta \theta d$ are available. The experimental values of $\Delta \theta d$ was found from the point of ignition to the point where an appreciable rise in cylinder pressure was noticeable, from the motored $P-\theta$ curve superimposed on the engine firing $P-\theta$ diagram

$$
\begin{aligned}
\Delta T & =h f g /[(A / F) * C p a+C p f] \\
\Delta P & =-p i * k * \Delta V / V+(p 3-p 2) *(V t d c / V i) *[(d / d t) M F B] \\
M F B & =1-\exp \left(-a *((\theta-\theta i) / \Delta \theta c)^{m+1}\right) \\
h c_{W} & =3 \cdot 26 * B^{-0 \cdot 2} * \Delta P^{0 \cdot 8} * T^{-0 \cdot 55} * V g^{0 \cdot 8} \\
k & =k r+(k p+k r) *[(d / d t) M F B] .
\end{aligned}
$$

Equation 9 is used to calculate the drop in temperature at intake manifold due to fuel vaporization. Equation 10 is used to calculate the rise in cylinder pressure if mass fraction burnt (MFB) is known or conversely to evaluate (MFB) from experimental $P-\theta$ diagram. Equation 11 is the Weibe model. Equation 12 is the Woshni's relation to evaluate the instantaneous 
heat transfer during combustion. Equation 13 gives variability in the polytropic index during combustion and expansion. A simple logic employed to estimate the spark advance, is to initially prompt the user for specifying the desired spark advance angle based on the inputs he has given regarding the operating conditions of the engine like inlet temperature and pressure, equivalence ratio, speed, compression ratio, bore to stroke ratio, etc. The program calculates the flame development angle corresponding to these inputs and modifies the spark advance for optimum output of the engine for specific engine geometry and operating conditions as entered by the user. This procedure is necessary because to determine the laminar flame speed, the temperature and gas pressure at the point of ignition is required. Further to calculate the flame development angle $(\Delta \theta d)$, the clearance height at ignition is also required.

The motored $P-\theta$ trace was obtained for these settings. Spark advance was adjusted to MBT and the corresponding $P-\theta$ trace was obtained, under WOT firing conditions. The flame development angle was established by super imposing the motored $P-\theta$ diagram over the corresponding $P-\theta$ diagram obtained under firing conditions for MBT setting of the spark advance for the given compression ratio. The above value of flame development angle was used as a basis for calculating the tentative value of the constant ' $C$ ', in equation 4 . This equation is the revised equation which still does not account for either the compression ratio or the F/A equivalence ratio.

The compression ratio was varied and for each compression ratio setting, the spark advance was set for MBT and the flame advance angle were determined as explained in the previous step and the results obtained were tabulated.

With the revised version of equation 4 , simulation was carried out by incorporating the same and running the C-program. The values predicted by the C-program with the revised equation 4 and the experimentally obtained values of the flame development angle (MBT setting), are tabulated (table 3 ).

The error between the experimental and simulated values of the flame development angle were minimised and a polynomial equation of $3^{\text {rd }}$ order was fit into the revised equation 4 .

The governor set-up was detached from the engine test rig and the carburetor float level was re-adjusted to give slight variations in the F/A equivalence ratios. The flame development angle was established by employing the same experimental procedure and the constant ' $\mathrm{C}$ ', was evaluated to be 0.21 for fuel equivalence ratio $>1.0$, and 0.40 for fuel equivalence ratio $<1.0$. The final form of the equation for the flame development angle is given as [for details, see references Harish Kumar \& Antony (2006; 2008)].

$$
\begin{aligned}
\Delta \theta_{d}= & C *(V p * \gamma)^{1 / 3} *\left(h / S_{l}\right)^{2 / 3}-((-3.129 * r) \\
& \left.+\left(0.9894 * r^{2}\right)-\left(0.06508 * r^{3}\right)\right)
\end{aligned}
$$

Table 3. Experimental and simulated values of flame development angle (FDA) and error.

\begin{tabular}{lccccccc}
\hline$r$ & FDA expt & FDA simu & Error & $r$ & FDA expt & FDA simu & Error \\
\hline 4.63 & 23 & 23.36 & 0.36 & 6.88 & 12 & 16.41 & 4.41 \\
5.10 & 20 & 21.56 & 1.56 & 7.40 & 10 & $15 \cdot 29$ & $5 \cdot 29$ \\
6.0 & 17 & 18.67 & 1.67 & 8.28 & 09 & 13.67 & 4.67 \\
& & & & 9.16 & 08 & 12.34 & 4.34 \\
\hline
\end{tabular}


Table 4. Computed MFB values at different points during progressive combustion.

\begin{tabular}{lcccccc}
\hline $\begin{array}{l}(\Theta-\Theta i) / \\
(\Delta \theta c)\end{array}$ & $\begin{array}{c}\text { MFB-CSP- } \\
\text { With swirl }\end{array}$ & $\begin{array}{c}\text { MFB-SSP- } \\
\text { With swirl }\end{array}$ & $\begin{array}{c}\text { MFB-SSP } \\
\text { No swirl }\end{array}$ & $\begin{array}{c}\text { MFB-rich } \\
\text { mixtures }\end{array}$ & $\begin{array}{c}(\Theta-\Theta i) / \\
(\Delta \theta c)\end{array}$ & $\begin{array}{c}\text { MFB-lean } \\
\text { mixtures }\end{array}$ \\
\hline 0.000 & 0.00 & 0.00 & 0.00 & 0.00 & 0.000 & 0.000 \\
0.166 & 0.05 & 0.02 & 0.01 & 0.009 & 0.125 & 0.005 \\
0.333 & 0.38 & 0.15 & 0.12 & 0.15 & 0.250 & 0.008 \\
0.500 & 0.80 & 0.40 & 0.35 & 0.48 & 0.375 & 0.020 \\
0.666 & 0.90 & 0.70 & 0.62 & 0.82 & 0.500 & 0.050 \\
0.833 & 0.95 & 0.82 & 0.80 & 0.95 & 0.625 & 0.300 \\
1.000 & 0.98 & 0.95 & 0.95 & 0.98 & 0.750 & 0.600 \\
& & & & & 0.875 & 0.800 \\
& & & & & 1.000 & 0.950 \\
\hline
\end{tabular}

With the new modified equations for predicting the overall combustion duration and ignition delay, a new set of 'logistic equation with conditional variability in the Mass-Fraction-Burnt', has been derived, which takes into account the influence of such factors as location of spark plug, engine geometry (bore/stroke ratio which is input by the user), intake generated swirl, use of dual spark plug, etc. The MFB values that have been computed using equation 1 and the experimental $P-\theta$ trace, are given in table 4. For details see Harish Kumar \& Antony (2008). From the experimental data above, a set of logistic equations have been derived.

$$
\begin{aligned}
& *(a) M F B= 1 /\{1+105 \cdot 4 * \exp [-12 \cdot 64 *((\Theta-\Theta i) /(\Delta \theta c))]\} \\
&- \text { Central SP, with swirl. } \\
& *(b) M F B=1 /\{1+97 \cdot 67 * \exp [-10 \cdot 73 *((\Theta-\Theta i) /(\Delta \theta c))]\}- \text { Central SP, without swirl. } \\
& *(c) M F B=1 /\{1+77 \cdot 26 * \exp [-8 \cdot 02 *((\Theta-\Theta i) /(\Delta \theta c))]\} \\
&- \text { Side SP, with swirl. } \\
& *(d) M F B=1 /\{1+74 \cdot 65 * \exp [-7 \cdot 28 *((\Theta-\Theta i) /(\Delta \theta c))]\} \\
&- \text { Side SP, without swirl. } \\
& *(e) M F B=1 /\{1+98 \cdot 47 * \exp [-13 \cdot 79 *((\Theta-\Theta i) /(\Delta \theta c))]\} \\
&- \text { Dual SP, without swirl. } \\
&- \text { Lean mixtures. } \\
&(f) M F B=1 /\{1+4901 * \exp [-12 \cdot 05 *((\Theta-\Theta i) /(\Delta \theta c))]\} \\
&- \text { Rich mixtures. } \\
&(g) M F B=1 /\{1+176 \cdot 2 * \exp [-10 \cdot 23 *((\Theta-\Theta i) /(\Delta \theta c))]\} \\
& * \text { near stochiometric F/A ratio. }
\end{aligned}
$$


Since the above modifications have been done mainly considering the influence of compression ratio, the possibility of the program code allowing for operation of the engine in damaging modes (as a result of knock) at higher compression ratios has to be eliminated. According to the 'Auto Ignition Theory', when the fuel-air mixture in the end gas region is compressed to sufficiently high pressures and high temperatures, the fuel oxidation process, starting with the preflame chemistry and ending with rapid energy release can occur spontaneously in parts of, or the entire end gas region. In other words, the phenomenon of knock occurs if there is enough time for sufficient auto ignition precursors to form. One way to model engine knock is to assume that there exists a critical mass fraction of precursors that if attained anywhere within the charge will cause auto ignition. Mathematically this can be expressed as

$$
\int(d x p / d t) d t=x c .
$$

$x p$ denotes the mass fraction of auto ignition precursors and xc denotes its critical value. The lower limit of integration is chosen to coincide with the closing of the inlet valve, thus ignoring the precursor formation in the intake manifold. The non dimensional rate of formation of auto ignition precursors is represented by an equation of the form given below

$$
(1 / x c)(d x p / d t)=A_{1} p_{u}^{-n 1} \exp \left(B_{1} / T_{u}\right) .
$$

$A_{1}, B_{1}, n_{1}$ are fitted parameters that depend on the engine characteristics and type of fuel used. $p_{u}, T_{u}$ are the pressure and temperature of the end gas. Among the many empirical relations proposed based on this principle, the most extensively tested correlation is the one proposed by Douaud \& Eyzat (1978) given as

$$
17 \cdot 68(O N / 100)^{3 \cdot 402} p_{u}^{-1 \cdot 7} \exp \left(3800 / T_{u}\right) .
$$

To incorporate the above model into an arbitrary heat release model of combustion, one defines the extent of reaction $(\zeta)$ as the ratio $(x p / x c)$ and

$$
(d \zeta / d t)=(1 / x c)(d x p / d t) .
$$

Equation 19 is integrated simultaneously with the energy and continuity equations. If at any time prior to the end of combustion, $(\zeta)$ reaches the value 1 , knock is said to occur and the remaining unburned gas burns instantaneously. An important step therefore is to characterise the end gas pressure and temperature and determine the temperature and pressure-time history of the end gas during an individual cycle. The end gas temperature and pressure are not uniform and their distribution vs. time is extremely complex. To simplify the procedure, often the mean unburned mixture temperature or alternately (in the absence of substantial heating of the end gas by the exhaust valves and piston), the core temperature, corresponding to the isentropic compression of the mixture from conditions at the start of compression are used.

In the present work, the following simplified procedure has been adopted to estimate the end gas pressure and temperature. The mass fraction burnt and the volume fraction occupied by the burned gas $\left(y_{b}\right)$ are related by the ideal gas law, by the equation

$$
\begin{aligned}
& M F B=\left\{1+\left(\rho_{u} / \rho_{u}\right)\left[\left(1 / y_{b}\right)-1\right]\right\}^{-1} \\
& V_{i}=V_{u}+V_{b} ; m=m_{u}+m_{b} ; y_{b}=V_{b} / V_{i} .
\end{aligned}
$$


The density ratio $\left(\rho_{u} / \rho_{u}\right) \approx 4.0$ (approximately) for general SI engine operating conditions. $V_{i}$ denotes the instantaneous cylinder volume at ignition which may be estimated, given the engine geometry and crank angle position $(\theta)$, using the equation given below,

$$
\begin{aligned}
V_{i}= & V_{d}\{[(r /(r-1))-((1-\cos (\theta)) / 2)+(l c / l s)] \\
& \left.-\left[0 \cdot 5 * \sqrt{ }(2 * l c / l s)^{2}-\sin ^{2}(\theta)\right]\right\}
\end{aligned}
$$

Thus, if MFB value is known, equations 20, 21 and 22, enable us to determine the values of $V_{u}$ and $V_{b}$. The instantaneous cylinder pressure (pi) taken as equivalent to the burned gas pressure, is related to the unburned/end gas pressure $(\mathrm{pu})$ assuming polytropic compression as follows

$$
p_{i} V_{b}^{k}=p_{u} V_{u}^{k}
$$

Temperature of the end gas is estimated by similar assumption

$$
T_{b} / T_{u}=\left(p_{i} / p_{u}\right)^{k-1 / k} .
$$

Equations 23 and 24, enable the pressure and temperature of the end gas to be determined from fundamental principles, which when substituted in equation 18, gives an approximate estimate of the induction time for auto ignition.

\section{Engine test rig}

A fully computerised, variable compression ratio, 4-Stroke, $256 \mathrm{cc}, 3000 \mathrm{rpm}$, SI-Engine with electronic ignition control and a governor for speed control has been used for conduction of experiments pertaining to the above research (figures $9 a-d)$. The compression ratio can be set to any value (even fractional values) with precision, as the test rig has a movable head under electronic motor control using a stepper motor and a precision manufactured Power Screw. In the present research, the compression ratio was varied as under, 4.63, 5.10, 6.0, $6 \cdot 88,7 \cdot 40,8 \cdot 28$, and $9 \cdot 16$. The experiments have been conducted at Wide-Open-Throttle (WOT) conditions, and near stoichiometric F/A ratios, unless otherwise mentioned. The rig also has a highly sensitive, water-cooled piezoelectric pressure sensor for accurate in cylinder pressure trace and temperature sensors for measuring temperature at strategic points in the operating cycle. The electronic ignition control system permits the ignition advance to be set for any operating conditions of the engine for maximum brake torque (MBT) conditions. Minor adjustments in the governor sleeve displacement and carburetor float level can be made for getting different fuel mixture strengths (or fuel equivalence ratios). A standard 16-bit data acquisition card connected to the personal computer handles all experimental data acquisition. The mass flow rate of air into the intake manifold is measured using an orifice provided on the intake plenum with a sensor fitted to it. The sensor sends the signal to data acquisition card which in turn is connected to the micro computer, for calculation of mass flow rate of air.

\section{Air-fuel (A/F) ratio measurement}

The test rig has a sophisticated flow sensor mounted at the outlet of the fuel tank at its base, opening into a pipe that has a burette by its side provided with inlet and outlet taps near 


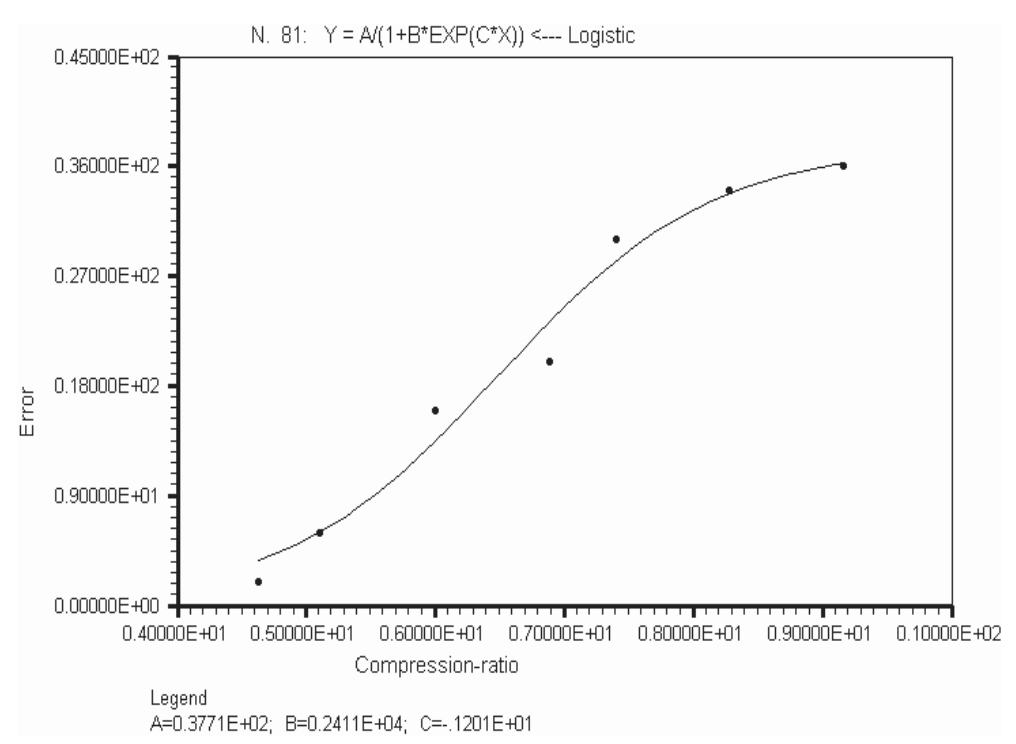

Figure 5. Total burn duration error plotted against compression ratio.

its bottom. The flow sensor provides an analog signal that is converted into a digital signal by the 16 bit A/D converter connected to the standalone 16 bit data acquisition card which communicates to the micro computer through the RS232 serial communication port.

The fuel flow rate could also be measured by the conventional method of letting the fuel from the fuel tank to fill up the burette by opening its inlet tap and closing it later while simultaneously noting down the volume of fuel consumed in certain period of time and determining the fuel flow rate.

The engine is equipped with an updraught type carburetor and the fuel equivalence ratios have been varied between 0.8 and 1.2 (approximately) by raising or lowering the carburetor float assembly with respect to the fuel nozzle.

\section{Results and discussion}

The graphs of figures $1-4$, show the plot of $\log (\mathrm{P})$ vs. $\log (\mathrm{V})$, from the experimental $P-\theta$ trace depicting the start of combustion (SOC) and end of combustion (EOC), for various compression ratios and for conditions where intake generated swirl in the intake manifold is present or not present. From a perusal of the graphs, it is clear that both compression ratio and intake generated swirl have a considerable influence on the overall burn duration during the combustion process, with the influence of compression ratio being more predominant. The influence of 'intake generated swirl' has however not been quantified in terms of the 'swirl ratio' and is therefore a limitation in this model.

The graphs of figures 5 and 6 show the plot of error vs. compression ratio for overall combustion duration and ignition delay respectively, based on the actual experimental values and that obtained under simulation using the pre-modified Taylor's equation for combustion duration and Keck's equation for ignition delay. This error has been minimised by incorporating them in these equations thereby leading to their respective modified forms which have been discussed in the previous topic. 


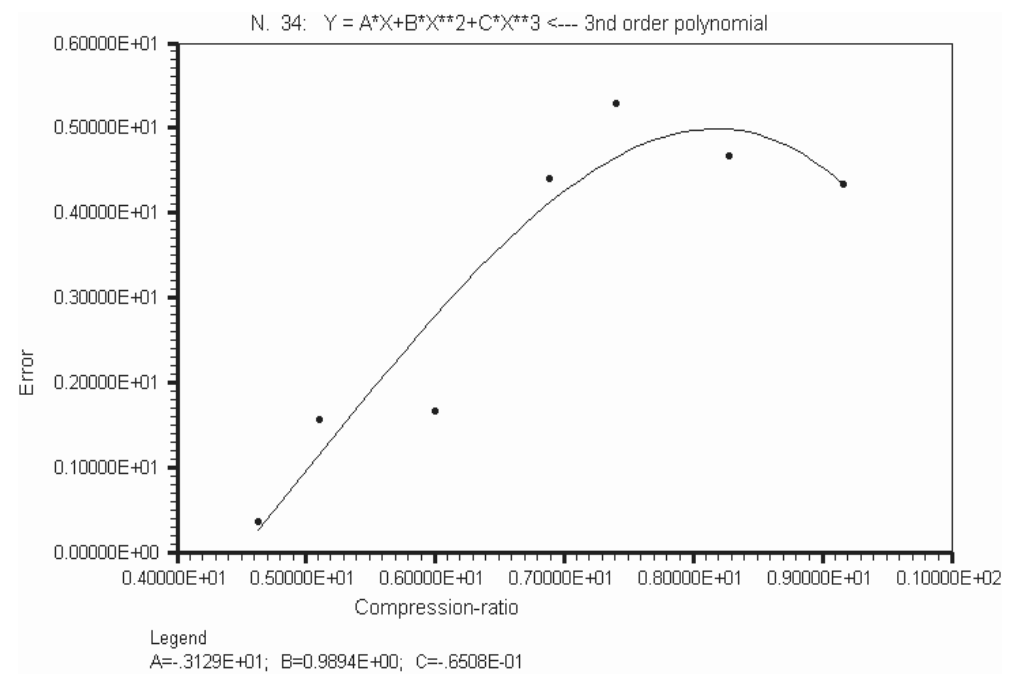

Figure 6. Error in ignition delay vs. compression ratio (for purpose of minimization).

The graphs of figure 7 show the improvement in the prediction of the ignition delay as the original Keck's equation is modified in two stages, by taking the influence of the compression ratio of the engine and later the fuel mixture strengths (or equivalence ratio) into account. This equation is also used to optimise the performance of the SI engine as it gives a measure of the optimum spark advance needed by simulating for MBT conditions of operation.

The graphs of figure 8 show the variation in the overall combustion duration with compression ratio of the engine and compares the values predicted by the original Taylor's equation and the simulation values obtained by the modified equation with the actual values as obtained

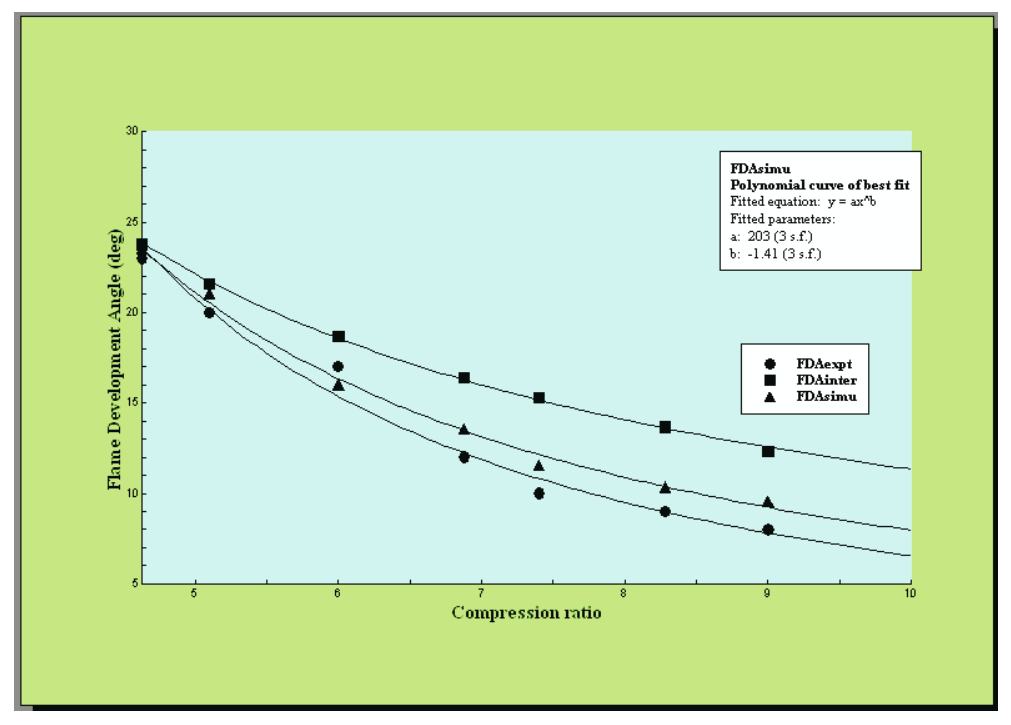

Figure 7. Flame development angle vs. compression ratio. 


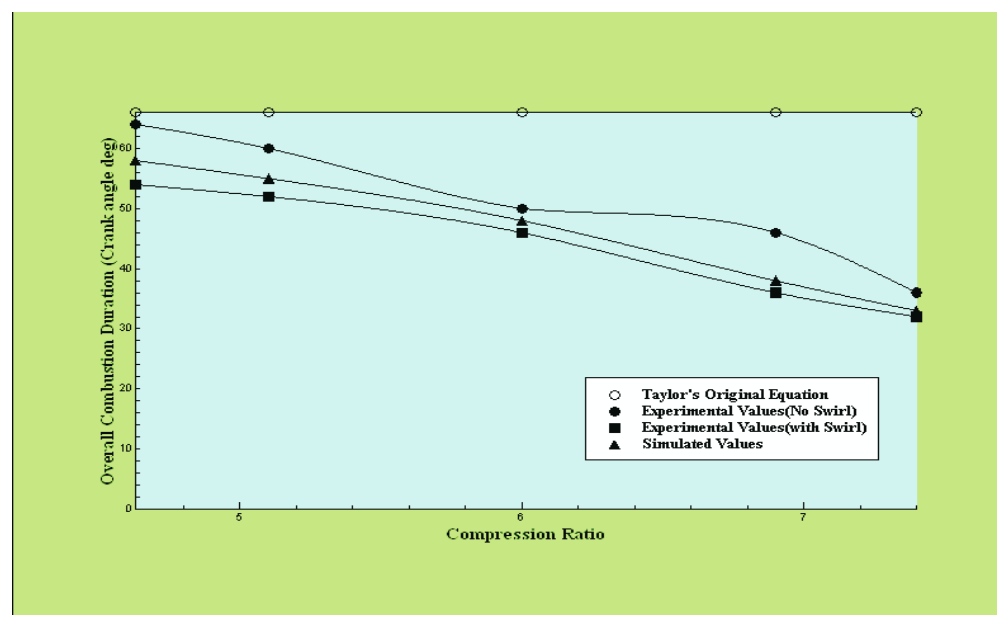

Figure 8. Overall combustion duration vs. compression ratio.

(a)

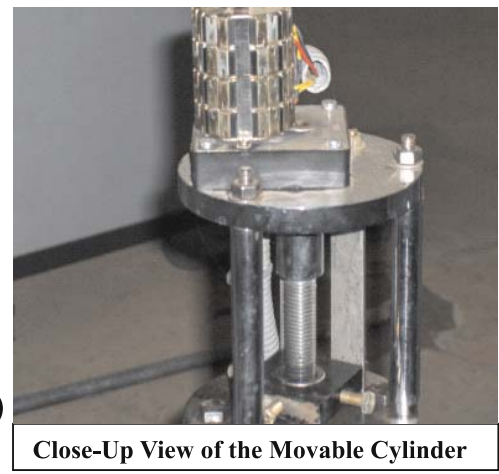

(c)

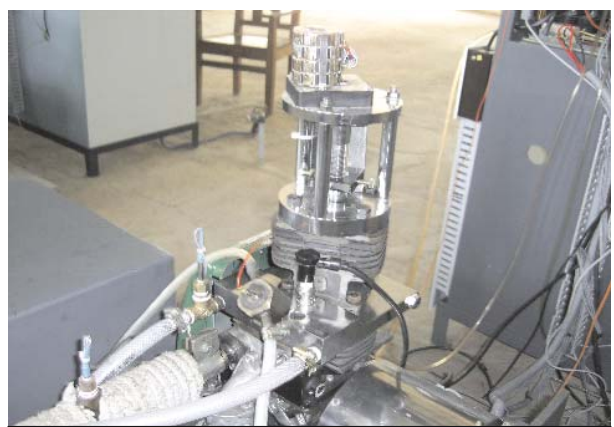

256cc, 3000rpm, Petrol Engine with Movable Head

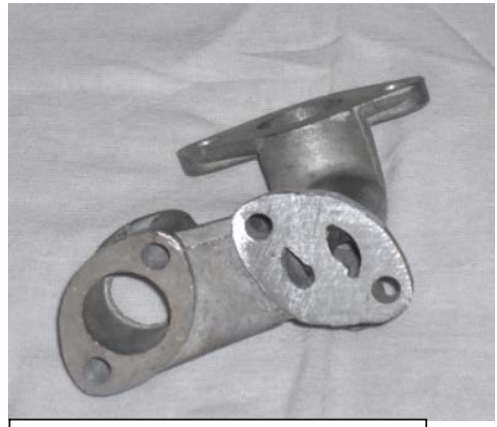

(b) Intake Manifold Part with Helical Grooves for Swirl

(d)

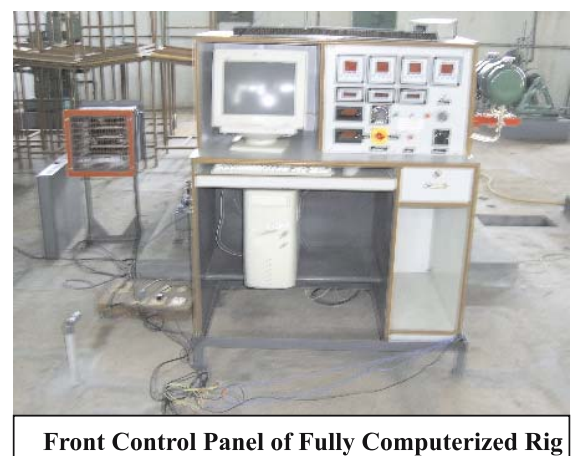

Figure 9. Experimental test rig. 
by the experimental test rig. The reduction in the error and the usefulness of the modified equation is clearly noticeable in the graph.

\section{Conclusions}

(i) The authors in this paper have made an attempt to improve the combustion simulation models particularly the empirical equations that are used to predict the overall combustion duration, ignition delay and MFB, for a more realistic simulation.

(ii) The equation proposed by Taylor to predict the overall combustion duration has been improved by including the influence of compression ratio, and the modified equation is $\Delta \theta c=\left(40+(5 *((n / 600)-1))+166 * \operatorname{pow}\left(((12 \cdot 5 / Y)-1 \cdot 1)^{2}\right)-(37 \cdot 71 /(1+(2411 *\right.$ $\exp (-1 \cdot 2 * r)))))$.

(iii) The equation propounded by Keck and coworkers to predict the flame development angle in SI engines has been improved by including the influence of compression ratio as $\Delta \theta d=C *(V p * \gamma)^{1 / 3} *\left(h / S_{l}\right)^{2 / 3}-\left((-3 \cdot 129 * r)+\left(0.9894 * r^{2}\right)-\left(0.06508 * r^{3}\right)\right)$.

(iv) A new equation for MFB, 'logistic equation with conditional variability in the massfraction-burnt', has been developed more precisely to predict the MFB/Heat release rate and thereby the incylinder pressures that are developed due to progressive combustion in SI engines. The influence of chamber geometry, sparkplug location and intake generated swirl have been accounted for in this new proposed model.

\section{Notations}

$\Delta P=$ Instantaneous cylinder pressure change during combustion

$\Delta T=$ Intake manifold temperature

$\Delta \theta_{c}=$ Total combustion duration specified in terms of crank angle

$\theta=$ Instantaneous crank angle

$\Delta \theta_{d}=$ flame development angle/ignition delay

$\theta i=$ Crank angle at the point of ignition

$\Phi=$ Fuel equivalence ratio (EQR)

$\rho_{u}, \rho_{b}=$ density of unburnt and burned gas respectively

$B=$ Cylinder bore

$C_{p a}=$ Specific heat of air

$h_{c W}=$ Instantaneous heat transfer coefficient), based on Woschni ‘s equation

$n=$ engine speed, rpm

$h_{f g}=$ Heat of vaporization of the fuel

$V_{d}=$ displacement volume of the cylinder

$h=$ clearance height at the point of ignition

$k=$ Effective polytropic index of compression/expansion during progressive combustion

$k_{p}=$ polytropic index of expansion for product gases

$k_{r}=$ polytropic index of compression/expansion for reactant mixture

$m=$ Mass of charge with suffixes $u$ and $b$ denoting unburnt and burnt fractions

$M F B=$ Mass fraction of burnt gases during progressive combustion

$l_{t}=$ Characteristic length (equal to bore)

$V, P=$ Instantaneous cylinder volume and pressure during combustion with suffix $i$ denoting instantaneous values

$p 2, p 3=$ Theoretical cylinder pressure at end of compression and combustion respectively

$S_{l}=$ Laminar flame speed

$S_{l o}, \alpha, \beta=$ Parameters used in equation 8 , to find laminar flame speed 
$T=$ Temperature (in deg K) with suffixes

$V_{t d c}=$ Cylinder volume at TDC

$V_{g}=$ Gas velocity during combustion

$V_{s}, P_{s}, V_{f}, P_{f}=$ cylinder volume and cylinder pressure at the start of combustion and end of combustion respectively

$l_{s}=$ stroke length

$V_{i}=$ Instantaneous cylinder volume at any crank angle

$n_{1}=$ total crank angle intervals for complete combustion

$Y=$ Number of moles of actual oxygen supplied to the engine

$l_{c}=$ Length of connecting rod

$Y_{c c}=$ Number of moles of chemically correct oxygen requirement during combustion

$r=$ Compression ratio

$r_{c}=$ crank radius

$\gamma=$ Kinematic viscosity

$i=$ suffix to designate instantaneous value or the start of ignition

$\xi=$ Characteristic burning time $\left(l_{t} / S_{l}\right)$

$\mu=$ Parametric mass entrained within the flame region that has yet to burn

$Z=$ Taylor's Mach Index (for design of intake and exhaust valves)

$M F B=$ Mass fraction of burned gas

$S O C=$ Start of Combustion

$E O C=$ End of Combustion.

\section{References}

Annand W J D 1971 A new computation model for combustion in SI-Engine. Proc. Inst. Mech. Eng. 185:

Ball J K, Raine R R, Stone C R 1988 Combustion analysis and cycle by cycle variation in SI-Engine combustion, Part 1: An evaluation of combustion analysis routines by reference to model data. Proc. Inst. Mech. Eng. Vol. 212. Part 2: A new parameter for completeness of combustion. Proc. Inst. Mech. Eng. 212: Part D

Blizard N C, Keck J C 1974 Experimental and theoretical investigation of turbulent burning model for IC-Engines, SAE Paper 740191. SAE Automotive Engineering Congress, Detroit

Douaud A M, Eyzat P 1978 'Four-Octane Number method for predicting the anti knock behaviour of fuels and engines. SAE Paper 780080, SAE Trans. 87

Harish Kumar R, Antony A J 2006 A simple approach to predict ignition delay for optimising SIEngine performance, paper no. IN_ 13. $3^{\text {rd }} B S M E-A S M E$ International Conference on thermal Engineering, $20^{\text {th }}$ to $22^{\text {nd }}$, Dhaka, Bangladesh

Harish Kumar R, Antony A J 2008 Progressive combustion in SI engines. SAE Technical Paper 2008-01-1630 (08SFL-0028) 'Written Paper', at the 2008 SAE International Powertrains, Fuels $\&$ Lubricants Congress, Shanghai, CHINA, June $23^{\text {rd }}$ to $25^{\text {th }}$

Heywood J B, Higgins J M, Watts P A, Tabaczynski R J 1979 Development and use of cycle simulation to predict SI-Engine efficiency and Nox emissions. SAE paper, 79021

Heywood J B, Pischinger S 1990 A model for flame kernel development in an SI- Engine. $23^{\text {rd }}$ International Symposium on Combustion

Hinze P C, Heywood J B 1992 A model for flame initiation and early development in SI-Engines and its application to cycle to cycle variations. paper 942049 , SAE, pp 1808-1815

Hinze P C, Heywood J B 1996 A study of cycle to cycle variation in SI-Engines using a modified quasi dimensional model. SAE paper 961187

Jensen J K, Schramm J 2000 A three zone heat release model for combustion analysis in a natural gas SI-Engine-Effects of crevices and cyclic variations on UHC emissions, Paper 200-01-2802. SAE 